\title{
Doxycycline: From Ocular Rosacea to COVID-19 Anosmia. New Insight Into the Coronavirus Outbreak
}

\author{
Chiara Bonzano ${ }^{1 *}$, Davide Borroni ${ }^{2}$, Andrea Lancia ${ }^{3}$ and Elisabetta Bonzano ${ }^{3,4}$ \\ ${ }^{1}$ Eye Clinic, DiNOGMI, University of Genoa and IRCCS San Martino Polyclinic Hospital, Genoa, Italy, ${ }^{2}$ Cornea Unit, Royal \\ Liverpool University Hospital, Liverpool, United Kingdom, ${ }^{3}$ Department of Radiation Oncology, IRCCS San Matteo Polyclinic \\ Foundation, Pavia, Italy, ${ }^{4}$ PhD School in Experimental Medicine, University of Pavia, Pavia, Italy
}

Keywords: COVID-19, doxycycline, coronavirus (CoV), SARS - CoV, anosmia

\section{INTRODUCTION}

Coronavirus Disease 19 (COVID-19) caused by Severe Acute Respiratory Syndrome-Coronavirus2 (SARS-CoV-2) it usually manifests with respiratory symptoms (1).

Similarly, to other human respiratory Coronaviruses (HCoV), it seems to have a neuroinvasive and neurotropic activity $(1,2)$. In the retrospective case series study conducted by Mao et al. three categories of neurological symptoms COVID19-related included central nervous system (CNS) manifestations, peripheral nervous system (PNS) symptoms and musculoskeletal disorders (2).

Hyposmia has been reported as a possible peripheral nervous system (PNS) symptom caused by

OPEN ACCESS

Edited by:

Zisis Kozlakidis,

International Agency For Research On

Cancer (IARC), France

Reviewed by:

Alexander Kasumyan, Lomonosov Moscow State

University, Russia

*Correspondence:

Chiara Bonzano

oculistabonzano@gmail.com

Specialty section:

This article was submitted to Infectious Diseases-Surveillance,

Prevention and Treatment,

a section of the journal

Frontiers in Medicine

Received: 31 March 2020

Accepted: 24 April 2020

Published: 08 May 2020

Citation:

Bonzano C, Borroni D, Lancia A and Bonzano E (2020) Doxycycline: From

Ocular Rosacea to COVID-19 Anosmia. New Insight Into the

Coronavirus Outbreak

Front. Med. 7:200.

doi: 10.3389/fmed.2020.00200
COVID-19 infection (2).

In our experience, the smell alteration (hyposmia, anosmia) seems to be one of the first manifestations of COVID-19 disease, with or without the loss of taste (dysgeusia). Sometimes it remains the only symptom; more often, it comes with fatigue, fever, and cough.

We provide a commentary on how COVID-19 could affect the sense of smell and the reason why doxycycline (Dox) could play a role in its recover.

\section{ANOSMIA}

The three leading causes of loss of smell reported in the literature are head trauma, chronic sinonasal inflammation and upper respiratory tract viral infections $(3,4)$. Anosmia is one between numerous olfactory disorders, but its mechanism is not clearly defined (3).

Post viral temporary chemosensory dysfunction after a common cold is widely reported $(3,5,6)$.

The swelling of the mucosa in the olfactory cleft it seems to be cause of the transient olfactory and taste loss typically reported during the common cold. It usually leads to a conductive post-viral loss of smell, and it usually appears 3 months after the upper respiratory tract infection (3).

The olfactory neuroepithelium represents an important immunological barrier within the nasal cavity exposed to the external environment, and thus it is subject to both exogenous insults and endogenous host defense responses (7).

In the pathogenesis of chronic rhinosinusitis (CRS)-associated olfactory loss, interferon (IFN) $\gamma$ signaling pathways may play a pivotal role in orchestrating immune system function. They are able to modulate inflammatory response and pattern-recognition receptors expressed by the innate immune system during infection (7). Therefore, they support an inflammatory process underlying the olfactory impairment CRS-linked (8). As evidence of this (CRS)-associated olfactory dysfunction is relatively rapidly reversed with systemic corticosteroids (9).

On the other side, some post-viral sense of smell impairment may be partly independent of nasal congestion, thus explaining oxymetazoline failure in improving olfaction (10).

Therefore, it has been suggested that $\mathrm{HCoV}$, thanks to their neuroinvasive, neurotropic, and neurovirulent properties may be able to induce neuronal impairment (11). 


\section{"Speed and Simplicity" of SARS-CoV-2}

Entering into the respiratory tract, all $\mathrm{HCoV}$ invade and infect intra-luminal macrophages and epithelial cells. $\mathrm{HCoV}$ belong to Coronaviridae, enveloped non-segmented, single-stranded, positive-sense RNA viruses (+)ssRNA. Viral spike (S) proteins manage their cell entry program. They act by binding cell-surface receptors and facilitating the fusion of the virus-cell membrane (12). The spike protein is the key of coronaviruses tropism (12). These $S$ proteins are organized in trimers that end up on the virion in a "corona" way giving it the characteristic crown-like look which seems to play a significative role in viral infection and pathogenesis (12). Similarly to SARS-coronavirus, SARS$\mathrm{CoV}-2$ seems able to enter in the respiratory epithelium (RE) by binding the human ACE2 receptor. Recombinant $S$ protein has been shown to interact with recombinant ACE2 protein (13). S proteins are the major antigenic determinant managing host immune networks, inhibiting antibodies and the immunity response against the virus by inactivating IFN- $\alpha$ and IFN- $\beta$ $(12,14)$. It is well-established the pivotal role of IFN to protect most tissues from viral pathogenicity. The speed and simplicity of SARS-CoV-2 are typical. Host survival in the presence of the viral infection depends on the efficacy of its IFN system; as a matter of fact, virus survival is linked to its capacity to replicate and spread in the host, by carrying out mechanisms of evasion or subversion of the host IFN response (15).

\section{New Insights Into the Doxycycline Activity}

IFN $\alpha / \beta$ signaling plays a protective role in reducing the virus spread and modulating $\mathrm{T}$ cell non-cytolytic antiviral response in limiting viral load. Moreover, some RNA-viruses have developed mechanisms to counteract innate host defense to establish productive infections in their hosts. This is the case of an RNA virus, the vesicular stomatitis virus (VSV) (16).

Retinoic acid-inducible gene I (RIG-I) and melanoma differentiation-associated gene-5 (Mda-5), seem to have an important role in the recognition of RNA viruses. In particular, it has been shown that immune signaling by RIG-I is involved in the generation of IFN- $\alpha / \beta$ following VSV infection. Under Dox treatment, cells released high levels of RIG-I proteins eliciting autonomous IFN response, thereby inhibiting viral infection in vitro (17).

In another RNA virus, the Respiratory Syncytial Virus (SRV), viral proteins inhibit IFN- $\alpha$ and IFN- $\beta$ to establish infection (18), and it has been reported a higher expression of interferoninduced protein only after minocycline administration. This suggests an increasing innate immune response supported by tetracycline and the following RSV inhibition (19).

The second-generation tetracycline Dox has an antiinflammatory and broad spectrum antimicrobial activity $(20,21)$.

In 1967, Dox was first approved by the FDA (20). It has minimal side effects and it is routinely prescribed for acne and rosacea. Dox is characterized by a $\sim 100 \%$ oral absorption and a prolonged serum half-life (18-22 h) (22).

In ophthalmology, Dox is usually administered in patients affected by ocular rosacea and posterior blepharitis (23). The Dox recommended dose is $40 \mathrm{mg}$ modified release once daily, which could be replaced by minocycline $100 \mathrm{mg}$, based on patient tolerance or particular requirements (24).

The rationale in its administration is proteolysis inhibition promoted by matrix metalloproteinases (MMPs) $(23,25)$. MMPs are involved in the regulation of chemical and biological process likes vascular remodeling and angiogenesis (26), so Dox also has anti-angiogenic properties. (27) It regulates cytokines and diminishes neutrophil chemotaxis too (28).

Besides its well-known use in treating bacterial infections, some studies in the literature report that Dox possesses a broad activity against viral infection too (29-31).

The first who described the Dox antiviral effect was Sturtz in 1998 (29), and this suggestion has been confirmed in several followed-up studies. $(16,32,33)$

Topno et al. demonstrated that Dox could interfere with the virion's replication, affecting its structure and causing inhibition of Japanese encephalitis virus-induced pathogenesis in vitro (32). The same observation is also reported in a study regarding VSV infection (16) and against the chikungunya virus (CHIKV) (33), suggesting that Dox might interfere with viral replication by aiming proteins essential for these viruses for a successful infection. As proof of that, computational literature reports the Dox ability to bind CHIKV cysteine protease (33), and to exert a significant inhibitory effect on DNV NS2B-NS3 serine protease in vitro (30); both these proteases proved to be able to catalyze viral polyproteins cleavage during infection. Moreover, some studies with $(+)$ ssRNA, Dengue virus (DNV), have demonstrated that Dox inhibits virus plaque assembly by interfering with the viral envelope conformational changes needed for virus entry (30). In both CHIKV and DNV, Dox seems to have the ability to bind virus envelop inhibiting viral entry into the cultured cells $(30,33)$.

Dox proved to be able to markedly decreased the virusinduced cytopathic effect (CPE) and significantly affect viral replication in a dose-dependent manner when used against Porcine Reproductive And Respiratory Syndrome virus (PRRSV) infection in cultured cells (31). Virus mRNA levels were strikingly reduced also in VSV-infected cells in response to Dox; both virus titers and the CPE of VSV infection were significantly influenced by Dox administration in a dose dependent manner (16).

\section{DISCUSSION}

Being the olfactory neural system able to regenerate throughout life, it can explain why the recovery of olfaction is common (34).

From our observation, anosmia affected mostly young adults rather than elderly patients, confirming existing findings in the literature $(35,36)$. It shows up more or less 6 days after fever, cough and muscle aches, but it can be the first and only symptom in many patients, with no mucosal swelling of the olfactory cleft, and that's why we hypothesize that it could be a possible PNS symptom as suggested (2). Among patients affected by PNS symptoms linked to COVID-19, the most common referred were hyposmia, hypogeusia, followed by neuralgia (2). Respiratory viruses such as rhinovirus and parainfluenza Epstein-Barr virus commonly could cause olfactory dysfunction (OD) by leading an inflammation in the olfactory mucosa resulting in rhinorrhea. 
Instead, COVID-19 seems to cause an atypical OD as it develops without rhinorrhea or nasal congestion (36).

In 2007, Suzuki et al. identified that coronavirus could be associated with anosmia, and he already speculated that nasal inflammation and related obstruction were not the only etiological factors underlying the OD in viral infection (37). As well-reported in the literature, $\mathrm{HCoV}$ could infect peripheral nerve terminals, using the trans-synaptic transfer to access the CNS $(36,38,39)$

In our preliminary observation, the administration of Dox $200 \mathrm{mg}$ once daily seems to improve respiratory symptoms and anosmia under Dox treatment in six patients completely recover after only 2 days of treatment. From our experience, it seems reasonable to continue the treatment at least 8 days. The mean patients' age was $35.8 \pm 6.8$ years, and $4(66.7 \%)$ were females. One patient reported anosmia as the only COVID-19 manifestation; instead of the other five patients who complained about the loss of smell, in which it appeared 5-7 days after mild fever, dry cough, and malaise. The average time of the recovery COVID-19-linked anosmia after the administration of Dox in these patients was $2.5 \pm 0.5$ days. We noticed a sudden improvement in all symptoms after the administration of Dox, but our most exciting insight is about the rapid recovery of the smell.

Unlike olfactory sensory neurons (OSNs), nasal epithelium, which includes the respiratory and olfactory epithelium (OE) expresses high levels of ACE2 (40). SARS-CoV-2 seems to target non-neural cell types in the peripheral olfactory system rather than directly enter OSNs, and it seems to be enough to generate cascading damage that could lead to the impairment of OSNs function altering the odor transduction which takes place on their cilia (40). The short-term COVID-19-linked anosmia reported in our experience supports the hypothesis that SARS-CoV2 affects the $\mathrm{OE}$, which can quickly renew and recover following

\section{REFERENCES}

1. Wu F, Zhao S, Yu B, Chen Y-M, Wang W, Song Z-G, et al. A new coronavirus associated with human respiratory disease in China. Nature. (2020) 579:2659. doi: 10.1038/s41586-020-2008-3

2. Mao L, Wang M, Chen S, He Q, Chang J, Hong C, et al. Neurological manifestations of hospitalized patients with COVID-19 in Wuhan, China: a retrospective case series study. Infect Dis. (2020) 12:e7352. doi: 10.1101/2020.02.22.20026500

3. Seo BS, Lee HJ, Mo J-H, Lee CH, Rhee C-S, Kim J-W. Treatment of postviral olfactory loss with glucocorticoids, ginkgo biloba, and mometasone nasal spray. Arch Otolaryngol Head Neck Surg. (2009) 135:1000. doi: 10.1001/archoto.2009.141

4. Seiden AM, Duncan HJ. The diagnosis of a conductive olfactory loss. Laryngoscope. (2001) 111:9-14. doi: 10.1097/00005537-200101000-00002

5. Wang JH, Kwon HJ, Jang YJ. Detection of parainfluenza virus 3 in turbinate epithelial cells of postviral olfactory dysfunction patients. Laryngoscope. (2007) 117:1445-9. doi: 10.1097/MLG.0b013e318063e878

6. Doty RL. Handbook of Olfaction and Gustation. Hoboken, NJ: John Wiley \& Sons, Inc. (2015).

7. Pozharskaya T, Lane AP. Interferon gamma causes olfactory dysfunction without concomitant neuroepithelial damage: IFN- $\gamma$ and inflammatory olfactory loss. Int Forum Allergy Rhinol. (2013) 3:861-5. doi: 10.1002/alr.21226 viral clearance (41). The average time to restore the sense of smell, most commonly reported in the literature, lasts from 1-8 days (36), if SARS-COV-2 could directly damage OSNs, recovery should take longer (42). Besides ACE2, Brann et al. also revealed that a cell-surface receptor, CD147, could play a role mediating SARS-CoV-2 cell entry (40). The expression of CD147 is detected in ciliated and goblet cells in the human nasal mucosa (43). Previous reports have shown that Dox has a significant inhibitory effect on CD147 expression (44, 45). Further studies are needed at present to define better if Dox has the ability to inhibiting viral entry by reduced CD147 expression levels. Moreover, thanks to its immunomodulatory and antiinflammatory properties, Dox could limit the pro-inflammatory state induced by the glial cells activated by the neurotropic virus, ensuring proper epithelial reconstitution in the $\mathrm{OE}(46,47)$. Given the possibility that COVID-19 occurs with the loss of smell and the evidence that corticosteroid may worsen the infection (48), Prof. Claire Hopkins, the British Rhinological Society president, recently suggested avoiding the use of these drugs in the therapeutic approach to the new-onset anosmia during the COVID-19 pandemic, especially if unrelated to previous head trauma or nasal pathology (48).

We are perfectly aware that there is a need for stronger evidence, but our article would intend to underline the importance of considering smell loss as a common symptom of COVID-19, supporting the rationale to treat such patients with Dox based on its interesting antiviral properties.

\section{AUTHOR CONTRIBUTIONS}

$\mathrm{CB}$ and $\mathrm{DB}$ : contributed equally to this manuscript, wrote the article, and reviewed the final version. $\mathrm{AL}$ and $\mathrm{EB}$ : review and editing of the final manuscript. All authors reviewed the manuscript and agreed with its content.
8. Morse JC, Shilts MH, Ely KA, Li P, Sheng Q, Huang L-C, et al. Patterns of olfactory dysfunction in chronic rhinosinusitis identified by hierarchical cluster analysis and machine learning algorithms: patterns of olfactory dysfunction in CRS. Int Forum Allergy Rhinol. (2019) 9:25564. doi: 10.1002/alr.22249

9. Welge-Lüssen A. Re-establishment of olfactory and taste functions. GMS Curr Top Otorhinolaryngol Head Neck Surg. (2005) 4:Doc06.

10. Hummel T, Rothbauer C, Pauli E, Kobal G. Effects of the nasal decongestant oxymetazoline on human olfactory and intranasal trigeminal function in acute rhinitis. Eur J Clin Pharmacol. (1998) 54:521-8. doi: 10.1007/s0022800 50507

11. Meessen-Pinard M, Le Coupanec A, Desforges M, Talbot PJ. Pivotal role of receptor-interacting protein kinase 1 and mixed lineage kinase domain-like in neuronal cell death induced by the human neuroinvasive coronavirus OC43. J Virol. (2017) 91:e01513-16. doi: 10.1128/JVI.01513-16

12. Belouzard S, Millet JK, Licitra BN, Whittaker GR. Mechanisms of coronavirus cell entry mediated by the viral spike protein. Viruses. (2012) 4:101133. doi: 10.3390/v4061011

13. Kuba K, Imai Y, Rao S, Gao H, Guo F, Guan B, et al. A crucial role of angiotensin converting enzyme 2 (ACE2) in SARS coronavirus-induced lung injury. Nat Med. (2005) 11:875-9. doi: 10.1038/nm1267

14. Heald-Sargent T, Gallagher T. Ready, set, fuse! The coronavirus spike protein and acquisition of fusion competence. Viruses. (2012) 4:55780. doi: $10.3390 / \mathrm{v} 4040557$ 
15. García-Sastre A. Ten strategies of interferon evasion by viruses. Cell Host Microbe. (2017) 22:176-84. doi: 10.1016/j.chom.2017.07.012

16. Wu Z, Wang X, Wei J, Li B, Shao D, Li Y, et al. Antiviral activity of doxycycline against vesicular stomatitis virus in vitro. FEMS Microbiol Lett. (2015) 362:fnv195. doi: 10.1093/femsle/fnv195

17. Liu G, Lu Y, Thulasi Raman SN, Xu F, Wu Q, Li Z, et al. Nuclear-resident RIGI senses viral replication inducing antiviral immunity. Nat Commun. (2018) 9:3199. doi: 10.1038/s41467-018-05745-w

18. Lo MS, Brazas RM, Holtzman MJ. Respiratory syncytial virus nonstructural proteins NS1 and NS2 mediate inhibition of stat2 expression and alpha/beta interferon responsiveness. J Virol. (2005) 79:9315-9. doi: 10.1128/JVI.79.14.9315-9319.2005

19. Bawage SS, Tiwari PM, Pillai S, Dennis VA, Singh SR. Antibiotic minocycline prevents respiratory syncytial virus infection. Viruses. (2019) 11:739. doi: 10.3390/v11080739

20. Cunha BA, Sibley CM, Ristuccia AM. Doxycycline. Therap Drug Monitor. (1982) 4:115. doi: 10.1097/00007691-198206000-00001

21. Saivin S, Houin G. Clinical pharmacokinetics of doxycycline and minocycline. Clin Pharmacokin. (1988) 15:35566. doi: 10.2165/00003088-198815060-00001

22. Scatena C, Roncella M, Di Paolo A, Aretini P, Menicagli M, Fanelli G, et al. Doxycycline, an inhibitor of mitochondrial biogenesis, effectively reduces cancer stem cells (CSCs) in early breast cancer patients: a clinical pilot study. Front Oncol. (2018) 8:452. doi: 10.3389/fonc.2018.00452

23. Sánchez J, Valentin S, Morales A, Rivera A. Safety and efficacy of doxycycline in the treatment of rosacea. Clin Cosmet Investig Dermatol. (2009) 2:12940. doi: 10.2147/CCID.S4296

24. van der Linden MMD, van Ratingen AR, van Rappard DC, Nieuwenburg SA, Spuls PhI. DOMINO, doxycycline $40 \mathrm{mg}$ vs. minocycline $100 \mathrm{mg}$ in the treatment of rosacea: a randomized, single-blinded, noninferiority trial, comparing efficacy and safety. Br J Dermatol. (2017) 176:146574. doi: $10.1111 /$ bjd. 15155

25. Dursun D, Kim MC, Solomon A, Pflugfelder SC. Treatment of recalcitrant recurrent corneal erosions with inhibitors of matrix metalloproteinase9, doxycycline and corticosteroids. Am J Ophthalmol. (2001) 132:813. doi: 10.1016/S0002-9394(01)00913-8

26. Liu J, Khalil RA. Matrix metalloproteinase inhibitors as investigational and therapeutic tools in unrestrained tissue remodeling and pathological disorders. In: Khalil RA, editor, Progress in Molecular Biology and Translational Science. Boston, MA: Elsevier. p. 355-420. doi: 10.1016/bs.pmbts.2017.04.003

27. Su W, Li Z, Li F, Chen X, Wan Q, Liang D. Doxycycline-mediated inhibition of corneal angiogenesis: an MMP-independent mechanism. Investig Opthalmol Visual Sci. (2013) 54:783. doi: 10.1167/iovs.12-10323

28. Henehan M, Montuno M, De Benedetto A. Doxycycline as an antiinflammatory agent: updates in dermatology. J Eur Acad Dermatol Venereol. (2017) 31:1800-8. doi: 10.1111/jdv.14345

29. Sturtz FG. Antimurine retroviral effect of doxycycline. Methods Find Exp Clin Pharmacol. (1998) 20:643. doi: 10.1358/mf.1998.20.8.4 87489

30. Rothan HA, Mohamed Z, Paydar M, Rahman NA, Yusof R. Inhibitory effect of doxycycline against dengue virus replication in vitro. Arch Virol. (2014) 159:711-8. doi: 10.1007/s00705-013-1880-7

31. Li Y, Wu Z, Liu K, Qi P, Xu J, Wei J, et al. Doxycycline enhances adsorption and inhibits early-stage replication of porcine reproductive and respiratory syndrome virus in vitro. FEMS Microbiol Lett. (2017) 364:fnx170. doi: 10.1093/femsle/fnx170

32. Topno R, Khan SA, Chowdhury P, Mahanta J. Pharmacodynamics of aminoglycosides and tetracycline derivatives against Japanese encephalitis virus. Asian Pacific J Trop Med. (2016) 9:2416. doi: 10.1016/j.apjtm.2016.01.033

33. Rothan HA, Bahrani H, Mohamed Z, Teoh TC, Shankar EM, Rahman NA, et al. A Combination of doxycycline and ribavirin alleviated chikungunya infection. PLoS ONE. (2015) 10:e0126360. doi: 10.1371/journal.pone.0126360
34. Beecher K, St John J, Chehrehasa F. Factors that modulate olfactory dysfunction. Neural Regen Res. (2018) 13:1151. doi: 10.4103/1673-5374.235018

35. Boesveldt S, Postma EM, Boak D, Welge-Luessen A, Schöpf V, Mainland JD, et al. Anosmia-a clinical review. Chem Senses. (2017) 42:51323. doi: 10.1093/chemse/bjx025

36. Lechien JR, Chiesa-Estomba CM, De Siati DR, Horoi M, Le Bon SD, Rodriguez A, et al. Olfactory and gustatory dysfunctions as a clinical presentation of mild-to-moderate forms of the coronavirus disease (COVID-19): a multicenter European study. Eur Arch Otorhinolaryngol. (2020). doi: 10.1007/s00405-020-05965-1

37. Suzuki M, Saito K, Min W-P, Vladau C, Toida K, Itoh H, et al. Identification of viruses in patients with postviral olfactory dysfunction. Laryngoscope. (2007) 117:272-7. doi: 10.1097/01.mlg.0000249922.37381.1e

38. Li Y, Bai W, Hashikawa T. The neuroinvasive potential of SARS-CoV2 may be at least partially responsible for the respiratory failure of COVID-19 patients. J Med Virol. (2020). 92:552-5 doi: 10.1002/jmv.25728

39. Baig AM, Khaleeq A, Ali U, Syeda H. Evidence of the COVID-19 virus targeting the CNS: tissue distribution, host-virus interaction, and proposed neurotropic mechanisms. ACS Chem Neurosci. (2020) 11:9958. doi: 10.1021/acschemneuro.0c00122

40. Brann DH, Tsukahara T, Weinreb C, Lipovsek M, Van den Berge K, Gong B, et al. Non-neuronal expression of SARS-CoV-2 entry genes in the olfactory system suggests mechanisms underlying COVID-19-associated anosmia. bioRxiv. (2020). doi: 10.1101/2020.03.25.009084

41. Yan CH, Faraji F, Prajapati DP, Boone CE, DeConde AS. Association of chemosensory dysfunction and Covid-19 in patients presenting with influenza-like symptoms. Int Forum Allergy Rhinol. (2020). doi: 10.1002/alr.22579. [Epub ahead of print].

42. Brann JH, Firestein SJ. A lifetime of neurogenesis in the olfactory system. Front Neurosci. (2014) 8:182. doi: 10.3389/fnins.2014.00182

43. Riethdorf S, Reimers N, Assmann V, Kornfeld J-W, Terracciano L, Sauter G, et al. High incidence of EMMPRIN expression in human tumors. Int J Cancer. (2006) 119:1800-10. doi: 10.1002/ijc.22062

44. Wang S, Liu C, Liu X, He Y, Shen D, Luo Q, et al. Effects of matrix metalloproteinase inhibitor doxycycline and CD147 antagonist peptide-9 on gallbladder carcinoma cell lines. Tumor Biol. (2017) 39:101042831771819. doi: 10.1177/1010428317718192

45. Rucci N, Millimaggi D, Mari M, Del Fattore A, Bologna M, Teti A, et al. Receptor activator of NF- B ligand enhances breast cancerinduced osteolytic lesions through upregulation of extracellular matrix metalloproteinase inducer/CD147. Cancer Res. (2010) 70:6150-60. doi: 10.1158/0008-5472.CAN-09-2758

46. Bohmwald K, Gálvez NMS, Ríos M, Kalergis AM. Neurologic alterations due to respiratory virus infections. Front Cell Neurosci. (2018) 12:386. doi: 10.3389/fncel.2018.00386

47. Shin J-M, Kang J-H, Lee S-A, Park I-H, Lee H-M. Effect of doxycycline on epithelial-mesenchymal transition via the p38/smad pathway in respiratory epithelial cells. Am J Rhinol Allergy. (2017) 31:71-7. doi: 10.2500/ajra.2017.31.4410

48. Claire H. Loss of Sense of Smell as Marker of COVID-19 Infection. Available online at: www.entuk.org

Conflict of Interest: The authors declare that the research was conducted in the absence of any commercial or financial relationships that could be construed as a potential conflict of interest.

Copyright (c) 2020 Bonzano, Borroni, Lancia and Bonzano. This is an open-access article distributed under the terms of the Creative Commons Attribution License (CC BY). The use, distribution or reproduction in other forums is permitted, provided the original author(s) and the copyright owner(s) are credited and that the original publication in this journal is cited, in accordance with accepted academic practice. No use, distribution or reproduction is permitted which does not comply with these terms. 